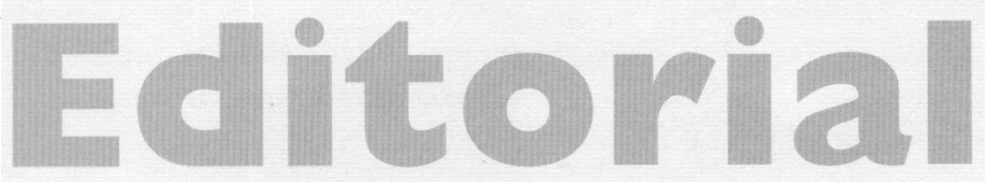

One of the themes of the forthcoming BIALL Annual Study Conference in Liverpool ( 14 to 17 June) arises from the happy coincidence that Liverpool was the venue for the very first BIALL Conference in 1970. The two conferences have a lot in common.

Of course, the surroundings were probably less sumptuous then (the University of Liverpool halls of residence provided the accommodation in 1970) than those which will be found by those attending proceedings at the Adelphi Hotel in June, but that was compensated for by the fact that the fee was only a tenner, and they are both "onevenue" events. Yes, the numbers involved in 1970 were much smaller, but still a third of the BIALL membership attended - a highly respectable attendance rate which is still reflected at conferences in the $21^{\text {st }}$ century. The 1970 Conference was a little shorter but the principle of combining the speakers' presentations with social events and a period for networking was established. In fact only the absence of law firm librarians really marks the two events apart - as I understand it, they were yet to be invented.

But that distinction is more than compensated by the one overwhelming common characteristic of the two events. The BIALL members in 1970 chose as the theme of the Conference "Law Librarianship - the next ten years", determining then that the true benefits of association, and to the Association, would arise from forward-thinking. 'That theme might have been the subtitle for every BIALL conference since I have been associated with the journal. Certainly, the 2002 Conference will be looking forward as it "revisits information technology"2 and looks at the ways technological advances affect the working lives of BIALL members. Clearly, it is in pooling ideas about future developments and comparing notes on how changes have been coped with, and even exploited, that members will gain value from their membership. I do not deny the need for elements of the trade association, lest excessive postage and packing or some other publishers' poll tax is imposed from on high, but BIALL is right to protect the Conference from being dominated by such issues. Only by including enough material to stimulate the grey matter will conference organisers ensure that the event avoids being a grey matter. ${ }^{3}$

I would like to think that this issue of the journal looks forward too and that it will stimulate thought in readiness for the Liverpool Conference. It begins appropriately by looking back at the life of the late Betty Moys, whose enormous contribution to the profession has been widely acknowledged. Betty would I am sure have been an avid consumer of the main contents of this issue, as it includes themes close to her fields of interest. The whole complicated area of $\mathrm{KM}$, intranets and taxonomies is covered - and these all give rise to stimulating (sometimes all together too stimulating) questions relating to classification and allocation of material. I suspect that a couple of the contributions to this issue will have a very long shelf-life in that they provide a very valuable source of reference on these topics. In the spirit of widening areas of interest, an article about a non-law issue, digitisation, is included - but I think there is more to it than mere interest as there are parallels in respect of legal materials.

I am indebted to all the contributors to this issue, but I am especially indebted to Kate Hodgson, who has done the lion's share of the work in recruiting authors and suggesting material. It has, as ever, been a pleasure to work with her.

\section{Laurence Eastham}

I. I acknowledge Mary Blake's excellent A History of the British and Irish Association of Law Librarians 1969-999 as the source of all my knowledge on BIALL's history. I believe that a few copies are still available for purchase from Susan Frost at BIALL Headquarters.

2. Although this is a second "revisit" for the Conference, the gap between this and the last visit to information technology is much shorter than the gap from the first Liverpool Conference to the second.

3. My apologies for this irresistible pun, but I deny all claims that the message was formulated merely to use it. 


\section{Library
information
Show}

\section{ExCeL London 25-26-27 June}

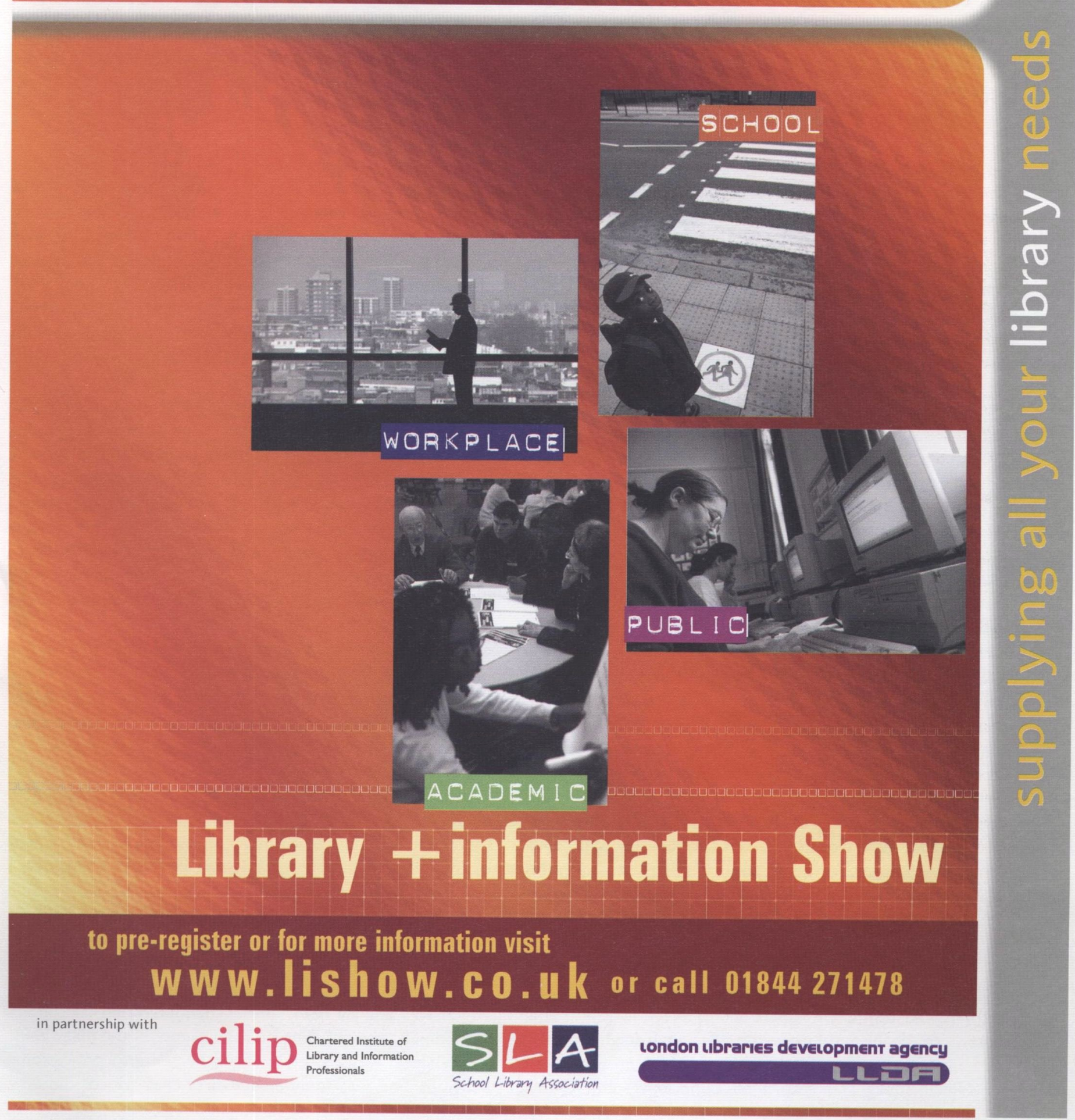

